\title{
Pioglitazone, a Peroxisome Proliferator-Activated Receptor- $\gamma$ Agonist, Attenuates Myocardial Ischemia/Reperfusion Injury in a Rat Model
}

\author{
Haruyasu Ito, Atsushi Nakano, Makoto Kinoshita, and Akira Matsumori \\ The Department of Cardiovascular Medicine, Kyoto University, Graduate School of Medicine, Kyoto, Japan
}

\begin{abstract}
SUMMARY: Thiazolidinediones are insulin-sensitizing drugs, ligands for peroxisome proliferator-activated receptor- $\gamma$ (PPAR- $\gamma$ ), which play an important role in the modulation of inflammatory responses. Myocardial ischemia/reperfusion (Ml/R) injury is associated with inflammation, in which various cells, particularly monocytes and macrophages, are involved. This study examined the effects of the thiazolidinedione peroxisome proliferator-activated receptor- $\gamma$ ligand, pioglitazone, in a rat model of MI/R injury. Pioglitazone at $3 \mathrm{mg} / \mathrm{kg} /$ day or the vehicle was administered for 7 days before rats were subjected to 30 minutes of coronary ligation followed by 24 hours of reperfusion. The mRNA expression [monocyte chemoattractant protein-1 (MCP-1) and intercellular adhesion molecule-1] in the ischemic region, the number of infiltrating macrophages in the ischemic region, and the myocardial infarct size were examined. The inhibitory effects of pioglitazone on activated macrophages were studied in vitro. Phorbol 12-myristate 13-acetate-induced MCP-1 production, in the absence or presence of pioglitazone, were assayed in cultured macrophages. Compared with the control group, (1) mRNA levels of MCP-1 and intercellular adhesion molecule-1 and the number of infiltrating macrophages in the ischemic region were significantly lower in the pioglitazone-treated group; and (2) myocardial infarct size was significantly smaller in the pioglitazone-treated group. Phorbol 12-myristate 13-acetate-stimulated cultured macrophages in the presence of pioglitazone produced significantly lower levels of MCP-1 than the stimulated control in the absence of pioglitazone. These observations demonstrate that pioglitazone has anti-inflammatory effects in $\mathrm{Ml} / \mathrm{R}$ injury that are independent of its insulin-sensitizing effect. (Lab Invest 2003, 83:1715-1721).
\end{abstract}

$T$ he peroxisome proliferator-activated receptor- $\gamma$ (PPAR- $\gamma$ ), a member of the nuclear receptor family of transcription factors (Lemberger et al, 1996), plays a pivotal role in adipocyte differentiation and glucose homeostasis (Chawla et al, 1994; Tontonoz et al, 1994). PPAR- $\gamma$ is activated by several prostanoids, a variety of nonsteroidal anti-inflammatory drugs (Lehmann et al, 1997), and thiazolidinediones (TZDs) (Lehmann et al, 1995). TZDs are insulin-sensitizing compounds used in the treatment of Type 2 diabetes mellitus. In addition to these antidiabetic properties, these compounds have potent effects in the control of inflammation, cell proliferation, and oncogenesis (Schoonjans and Auwerx, 2000). Thiazolidinedione PPAR- $\gamma$ agonists can inhibit the expression of various inflammatory cytokines produced by activated monocytes and macrophages (Jiang et al, 1998; Ricote et al, 1998), primarily by preventing the activation of the transcription factors. At this point, synthetic PPAR- $\gamma$ ligands may be of therapeutic value when activated macrophages participate in the pathogenesis of diseases. There is growing evidence that myocardial ischemia elicits an acute inflammatory state strongly accentuated by reperfusion (Braunwald and Kloner,

DOI: 10.1097/01.LAB.0000106724.29121.DA

Received July 9, 2003.

Address reprint requests to: Dr. A. Matsumori, Department of Cardiovascular Medicine, Kyoto University, 54 Kawara-cho Shogoin, Sakyou-ku, Kyoto606-8397, Japan.E-mail:amat@kuhp.kyoto-u.ac.jp
1985). In addition, the importance of the role played by macrophages in myocardial reperfusion injury has recently been clarified (Kakio et al, 2000; Ono et al, 1999). Most of the recruitment of activated monocytes to the inflammatory site is mediated by monocyte chemoattractant protein-1 (MCP-1) (Robinson et al, 1989; Rollins et al, 1989). In a recent study, the expression of MCP-1 in myocardial tissue of rats subjected to myocardial ischemia/reperfusion (MI/R) increased in the early phase of reperfusion (Kakio et al, 2000). The ischemic myocardium attracts both granulocytes and monocytes, and prevention of their infiltration may, at least partially, limit the extent of myocardial damage in the early inflammatory phase. This study shows that pioglitazone hydrochloride, a TZD, attenuates $\mathrm{MI} / \mathrm{R}$ injury in a rat model by reducing the expression of MCP-1. In addition, we demonstrate that the production of MCP-1 induced by phorbol 12-myristate 13-acetate (PMA) can be inhibited by pioglitazone in mouse macrophage cell lines.

\section{Results}

\section{Gene Expression in MI/R Injury}

We first examined whether the oral administration of pioglitazone inhibits the mRNA expression of MCP-1 and intercellular adhesion molecule-1 (ICAM-1) in myocardium exposed to 30 minutes of ischemia followed by 24 hours of reperfusion. These experiments demonstrated an increase in mRNA levels of MCP-1 
by $M I / R$ in the myocardium. A significant increase in the expression of MCP-1 mRNA was observed in the ischemic-reperfused region compared with myocardium of sham-operated rats after 24 hours of reperfusion $(0.51 \pm 0.07$ versus $0.02 \pm 0.002, p<0.01$; Fig. 1A). Pioglitazone inhibited the expression of MCP-1 mRNA in the ischemic-reperfused region in a dosedependent manner (Fig. 1A) and caused a significant inhibition of mRNA levels of MCP-1 in the ischemicreperfused region at a dose of $3 \mathrm{mg} / \mathrm{kg} /$ day compared with the vehicle $(0.23 \pm 0.06$ versus $0.51 \pm 0.07, p<$ 0.05; Fig. 1A). In addition, ICAM-1 mRNA in the myocardium was markedly increased by $M I / R$. The

Ischemic-reperfused region

A

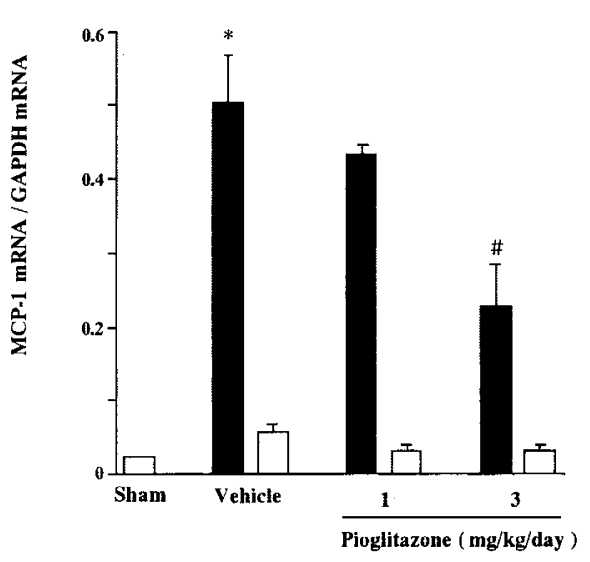

B

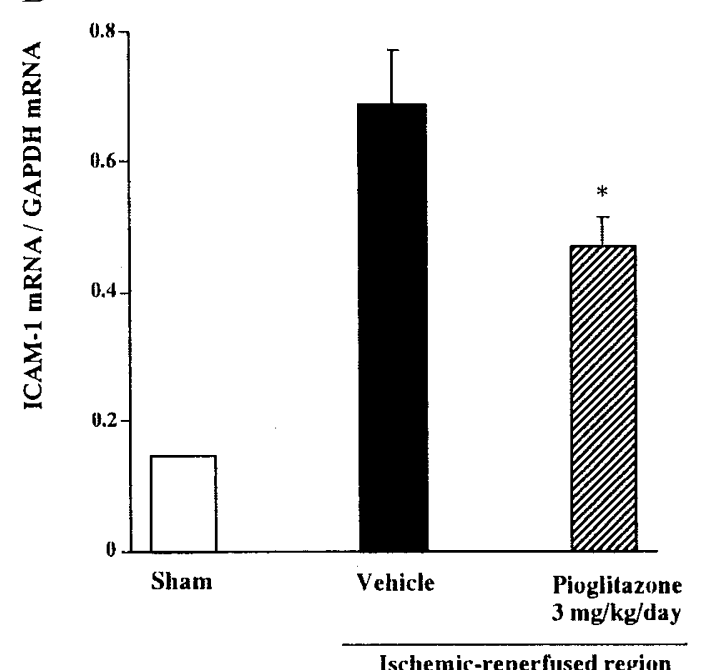

Figure 1.

Gene expression in ischemic-reperfused myocardium of rats treated with pioglitazone. A, Effects of pioglitazone on monocyte chemoattractant protein-1 (MCP-1) mRNA expression in ischemic and nonischemic myocardium of rats at 24 hours after ischemia and reperfusion. $n=3$, sham operated group; $n=$ 5 , treated group ( $1 \mathrm{mg} / \mathrm{kg} /$ day); $n=6$, vehicle group and treated group ( 3 $\mathrm{mg} / \mathrm{kg} /$ day). ${ }^{*} p<0.01$ versus sham-operated control; ${ }^{\#} p<0.01$ versus ischemic-reperfused region of the group treated with vehicle only. $B$, Effects of pioglitazone on intercellular adhesion molecule-1 (ICAM-1) mRNA expression in ischemic-reperfused myocardium of rats, 24 hours after ischemiareperfusion. Values are expressed as mean \pm SEM. $n=7$, each group. ${ }^{*} p<0.05$ versus ischemic-reperfused region in the group treated with the vehicle only. expression of ICAM-1 mRNA in the ischemicreperfused region after 24 hours of reperfusion was significantly lower in the group treated with pioglitazone at $3 \mathrm{mg} / \mathrm{kg} /$ day $(0.47 \pm 0.04)$ than in the group treated with the vehicle $(0.69 \pm 0.08, p<0.05$; Fig. 1B). These data indicate that pioglitazone may regulate important molecules involved in the acute inflammatory response to myocardial ischemia.

\section{Immunohistochemical Analysis of Infiltrating Macrophages}

We next verified that the administration of pioglitazone lessens the infiltration of macrophages in the ischemic-reperfused region, 24 hours after reperfusion. We performed immunohistochemical studies with an anti-activated macrophage antibody to estimate the extent of macrophage infiltration in the cardiac tissue (Fig. 2). These activated macrophages were distributed widely from the center to the border of the ischemic-reperfused region. The number of infiltrating macrophages was significantly lower in the actively treated group compared with the vehicletreated group $\left(304 \pm 21 / \mathrm{mm}^{2}\right.$ versus $462 \pm 23 / \mathrm{mm}^{2}$, $p<0.01$; Table 1).

\section{Myocardial Infarct Size}

To confirm that the inhibitory effects of pioglitazone on the expression of both MCP-1 and ICAM-1 mRNA in the ischemic-reperfused region were accompanied by measurable effects on pathologic findings, we examined the effect of pioglitazone on myocardial infarct size by the triphenyl tetrazolium chloride-Evans blue method. There was no significant difference in the size of area at risk between the vehicle-treated group and the actively treated group (Fig. 3), confirming that comparable amounts of cardiac tissue were jeopardized by MI/R. In the group treated with pioglitazone, the infarct size, expressed as a percentage of the weight of area at risk, was significantly smaller than in the group treated with the vehicle only $(44.4 \pm 2.0 \%$ versus $63.1 \pm 1.7 \%, p<0.001$; Fig. 3). Comparable results were obtained when infarct size was expressed as a percentage of the entire left ventricular weight $(23.4 \pm 1.1 \%$ in the group treated with pioglitazone versus $37.1 \pm 1.5 \%$ in the group treated with the vehicle only, $p<0.001$; Fig. 3). These data confirmed a protective effect of pioglitazone against myocardial damage in vivo.

\section{Concentration-Dependent Inhibition of PMA-Induced MCP-1 by Pioglitazone in Macrophages In Vitro}

Because pioglitazone reduced the expression of MCP-1 in inflammatory states in vivo, we examined whether it has similar inhibitory effects on activated macrophages in vitro. Stimulation with PMA can induce the production of MCP-1 in various cell types (Haslinger et al, 2001; Kakizaki et al, 1995). We stimulated RAW 264.7 macrophages with 25 nM PMA in the absence or presence of pioglitazone and measured the concentration of MCP-1 in the supernatants 

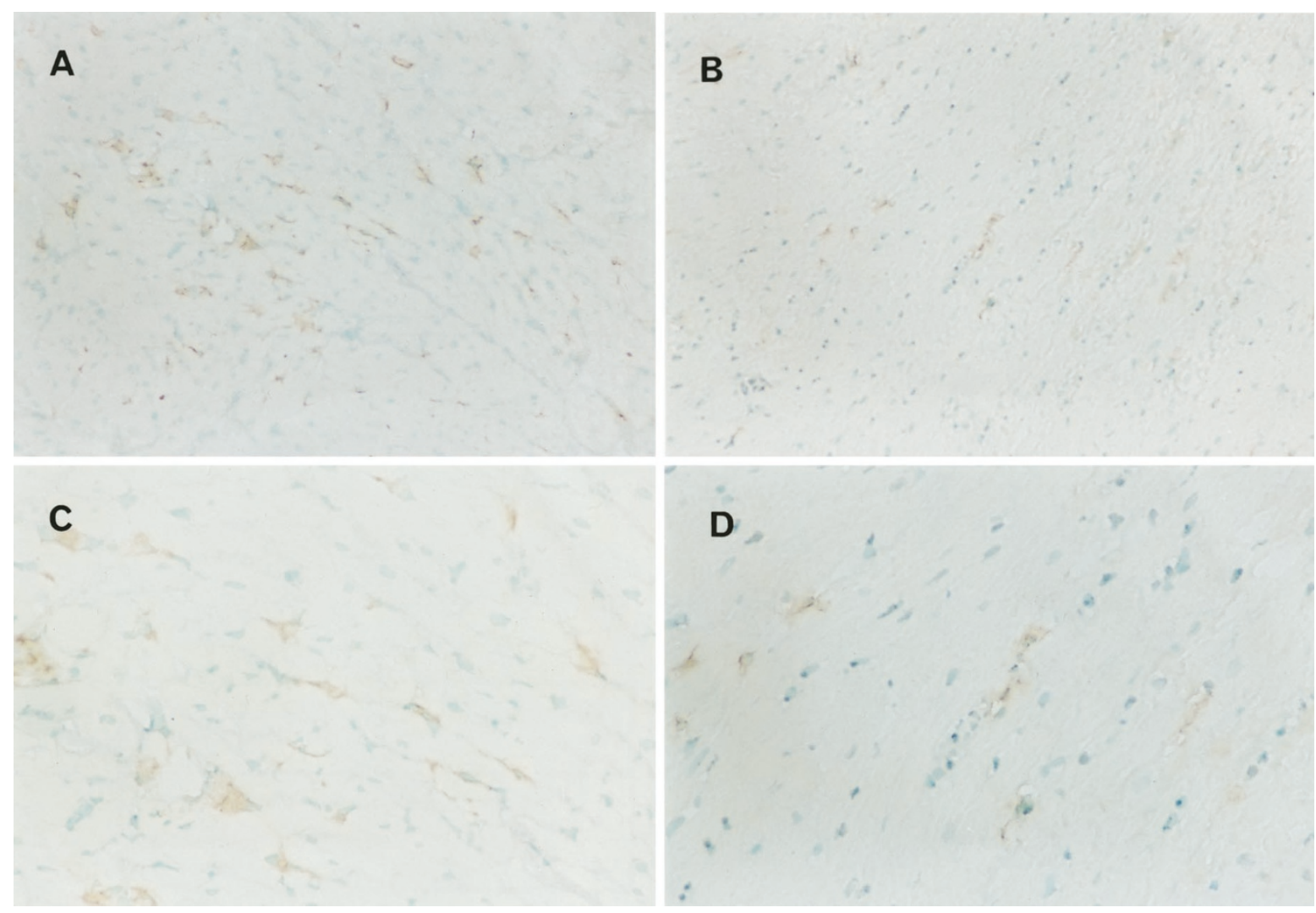

\section{Figure 2.}

Immunohistochemical analyses of infiltrating macrophages at 24 hours after reperfusion. Representative photomicrographs of cross-sections of myocardium stained with Ki-M2R as anti-activated macrophage antibody. A and C, Vehicle-treated rat; B and D, pioglitazone-treated rat. A and B, Original magnification, $\times 100 ; C$ and D, original magnification, $\times 200$.

Table 1. Effect of Pioglitazone on the Number of Infiltrating Macrophages

\begin{tabular}{ccc}
\hline & $\begin{array}{c}\text { Vehicle } \\
(n=4)\end{array}$ & $\begin{array}{c}\text { Pioglitazone, } \\
3 \mathrm{mg} / \mathrm{kg} / \text { day } \\
(n=4)\end{array}$ \\
\hline Macrophages $/ \mathrm{mm}^{2}$ & $462 \pm 23$ & $304 \pm 21^{*}$ \\
\hline
\end{tabular}

Values are means \pm SEM

${ }^{*} p<0.01$ versus the vehicle-treated group.

by ELISA. Cells stimulated with PMA alone increased the levels of MCP-1. In contrast, cells stimulated with PMA in the presence of pioglitazone produced significantly lower levels of MCP-1 (10 $\mu \mathrm{M}, 573 \pm 18 \mathrm{pg} / \mathrm{mL})$ than the stimulated controls $(896 \pm 8 \mathrm{pg} / \mathrm{mL}, P<0.05$; Fig. 4).

\section{Discussion}

Diabetes mellitus is a major coronary risk factor, and its long-term treatment with the insulin-sensitizing drugs, TZDs, lowers mortality and rates of ischemic cardiovascular events in patients with coronary artery disease. In addition, there is growing interest in the ability of TZDs to attenuate various inflammatory diseases through the modulation of the production of inflammatory cytokines. The results of our study demonstrate that pioglitazone has inhibitory effects on the
Vehicle

Pioglitazone ( $3 \mathrm{mg} / \mathrm{kg} / \mathrm{day})$

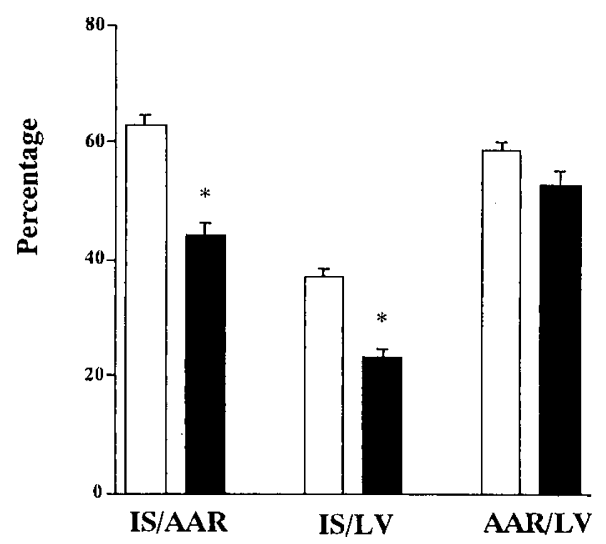

Figure 3.

Decrease in extent of myocardial injury by pioglitazone. $I S / A A R=$ infarct size indexed to area at risk; $I S / L V=$ infarct size indexed to left ventricle; $A A R / L V$ $=$ area at risk indexed to left ventricle. Open bars $=$ group treated with vehicle; closed bars = group treated with pioglitazone. The results of eight rats in each group were analyzed. ${ }^{*} p<0.001$ versus vehicle.

inflammatory reaction associated with $\mathrm{MI} / \mathrm{R}$ injury and that pioglitazone decreases the extent of myocardial injury in a rat model. 


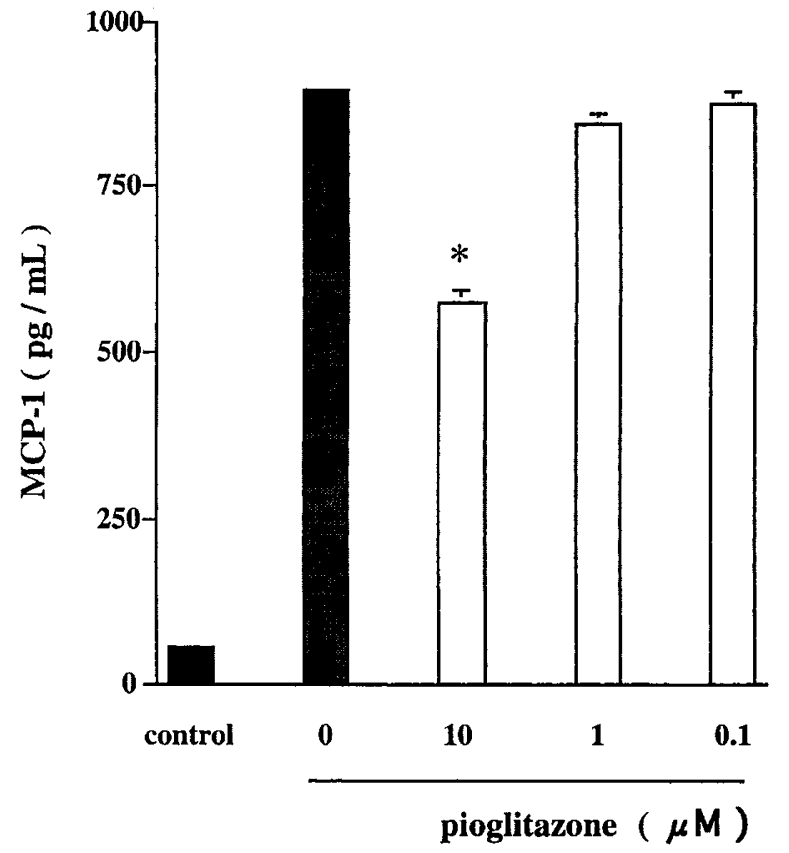

Figure 4.

Effect of pioglitazone on the production of MCP-1 by phorbol 12-myristate 13-acetate (PMA)-induced RAW 264.7 cells. RAW 264.7 cells were stimulated with PMA (25 nм) for 24 hours in the absence or presence of pioglitazone. These experiments were repeated three times with similar results. ${ }^{*} p<0.05$ versus stimulated control.

The important role played by MCP-1 in inflammatory and immune cardiovascular disorders has become increasingly apparent (Behr et al, 2000; Shioi et al, 1997). Recent studies from our laboratories have shown that plasma concentrations of MCP-1 are increased in the early phase of human acute myocardial infarction (Matsumori et al, 1997) and that an antibody against $\mathrm{MCP}-1$ reduces myocardial infarct size in rats subjected to Ml/R (Ono et al, 1999). In this study, we observed that pioglitazone attenuates the expression of MCP-1 and ICAM-1 mRNA in ischemic myocardium. MCP-1 induces the release of lysosomal enzymes and the generation of superoxide anions from macrophages involved in the tissue injury associated with MI/R (Zachariae et al, 1990). Furthermore, MCP-1 induces the expression of ICAM-1 in cardiac myocytes (Ban et al, 1994) and vascular smooth muscle cells (Ikeda et al, 1993). ICAM-1 is also a therapeutic target in $\mathrm{MI} / \mathrm{R}$ injury, because an increased expression of ICAM-1 mRNA has been observed in the viable border zone surrounding the necrotic area in a canine model of MI/R injury (Hartman et al, 1995; Kukielka et al, 1993) and because an anti-ICAM-1 antibody reduced the size of infarction (loculano et al, 1994). A lesser infiltration by macrophages may explain such beneficial effects because they may be the main source of inflammatory cytokines in MI/R (Herskowitz et al, 1995).

Our studies indicate that the administration of pioglitazone also reduces the PMA-induced production of MCP-1 in the supernatants from RAW 264.7 macrophages. Previous reports have shown that the induction of MCP- 1 by PMA, serving as a protein kinase
C activator, can be detected in various other cell types (Haslinger et al, 2001; Kakizaki et al, 1995). This effect of the TZD compound on inhibition of proinflammatory cytokines is observed with different kinds of TZDs currently used in clinical medicine (Su et al, 1999; Uchimura et al, 2001). It is, however, noteworthy that the potency of TZDs varies widely depending on the form of these compounds. Previous reports have demonstrated that troglitazone, one of the TZDs, shows differential activation of PPAR- $\gamma$ from rosiglitazone (Camp et al, 2000), suggesting that these two compounds cause a different recruitment of coactivator. The observation that TZDs can have distinct effects on the receptor raises the possibility that different PPAR- $\gamma$ ligands have distinct biologic downstream effects in different cell types. In addition, we have found that pioglitazone does not modify nuclear factor- $\kappa$ B activity in luciferase assay using A549 cells, a human epithelium-like lung carcinoma cell line stimulated with PMA (data not shown). At this point, troglitazone is known to inhibit nuclear factor- $\kappa \mathrm{B}$ activity and sequentially suppress proinflammatory cytokine production in several cell types (Desreumaux et al, 2001; Uchimura et al, 2001). This difference could be caused by variations in the amount of specific coactivators or other mechanisms independent of PPAR- $\gamma$ activation.

In a recent study, rosiglitazone was cardioprotective by reducing the expression of MCP-1 mRNA in the same rat model as ours (Yue et al, 2001). Despite its much lower binding affinity to PPAR- $\gamma$ than rosiglitazone, pioglitazone offered a similar degree of cardioprotection when administered in doses equivalent to those of rosiglitazone used in this study. This observation raises two points of discussion. First, recent study found that PPAR- $\alpha$ agonism was cardioprotective in a rat model of MI/R injury (Wayman et al, 2002). According to another report, pioglitazone has higher binding affinity to PPAR- $\alpha$ compared with rosiglitazone (Sakamoto et al, 2000). The anti-inflammatory effect of TZDs on MI/R injury may be mediated, at least partially, independently of PPAR- $\gamma$ activation (for example, by activation of the PPAR- $\alpha$ pathway). Second, the plasma concentration of pioglitazone was $3.97 \mu \mathrm{g} / \mathrm{ml}$ at 4 hours after administration of $3 \mathrm{mg} / \mathrm{kg}$ in rats, and it decreased with a $t_{1 / 2}$ of 6 hours (Maeshiba et al, 1997). The concentrations of pioglitazone in the hearts of rats after administration of 0.5 $\mathrm{mg} / \mathrm{kg}$ were $0.30,0.37$, and $0.17 \mu \mathrm{g} / \mathrm{ml}$ at 2,6 , and 10 hours, respectively. Because $10 \mu \mathrm{M}$ of pioglitazone is equivalent to $3.92 \mu \mathrm{g} / \mathrm{ml}$, the concentration that inhibited MCP-1 production in vivo in our experiments was appropriate. The precise mechanism by which pioglitazone modulates the production of MCP-1 is not clearly understood, and further studies are needed to clarify the anti-inflammatory properties of TZDs. Our study demonstrated that pioglitazone can exert antiinflammatory effects in vivo and in vitro independently of its insulin-sensitizing properties. Therefore, TZDs may be therapeutic in the inflammatory response to $\mathrm{MI} / \mathrm{R}$. 


\section{Materials and Methods}

\section{MI/R Model}

Male Wistar rats weighing 250 to 300 gm were anesthetized by intraperitoneal injection of sodium pentobarbital $(50 \mathrm{mg} / \mathrm{kg})$, intubated, and ventilated with a volume-cycled small-animal respirator. The heart was exposed via a left anterior thoracotomy, and the left anterior descending artery was ligated proximally with a 7-0 silk suture for 30 minutes, after which the ligature was released. After 24 hours of reperfusion, the left ventricle was dissected to separate nonischemic from ischemic-reperfused myocardium. The study was performed in accordance with the guidelines of the Guide for the Care and Use of Laboratory Animals published by the National Institutes of Health.

\section{Reagent Administration}

Pioglitazone hydrochloride was synthesized by Takeda Chemical Industries, Ltd., Osaka, Japan. It was prepared as an oral suspension in $0.5 \%$ methylcellulose solution. Zero, 1 , and $3 \mathrm{mg} / \mathrm{kg} /$ day of pioglitazone were administered by forced feeding once daily, starting 7 days before the operation.

\section{RNA Preparation and First-Strand cDNA Synthesis}

In the MCP-1 mRNA expression experiments, total RNA was isolated by a guanidinium thiocyanate/phenol/chloroform/isoamyl alcohol procedure from the nonischemic and ischemic-reperfused myocardium of the rats in each group. In the ICAM-1 mRNA expression experiments, total RNA was isolated from the ischemic-reperfused myocardium from the group of rats treated with the vehicle and from the group treated with pioglitazone ( $3 \mathrm{mg} / \mathrm{kg} /$ day). The RNA concentration was measured spectrophotochemically. First-strand cDNA was synthesized by the SUPERSCRIPT Preamplification System for First Strand cDNA Synthesis (GIBCO BRL) according to the manufacturer's protocol.

\section{Real-Time Semiquantitative RT-PCR Analysis}

Two microliters of the first-strand cDNA was used in the following assay. Real-time PCR using a TaqMan PCR Core Reagent Kit (Perkin-Elmer Corporation) was performed according to the manufacturer's protocol. Fluorescent signals generated by the reporter dye can be directly monitored by the ABI PRISM 7700 Sequence Detection System (Perkin-Elmer). The following forward $(F)$ and reverse $(R)$ primers and TaqMan probes $(P)$ were used for the quantification of rat MCP-1, rat ICAM-1, and rat glyceraldehyde-3-phosphate dehydrogenase (GAPDH) mRNA: MCP-1 (F), 5'GCTGCTACTCATTCACTGGCAA-3'; MCP-1 (R), 5'CTGCTGCTGCTGATTCTCTTGT-3'; MCP-1 (P), 5'TGATCCCAATGAGTCGGCTGGAGAA-3'; ICAM-1 (F), 5'-AAACGGGAGATGAATGGTACCTAC-3'; ICAM-1 (R), 5'-TGCACGTCCCTGGTGATACTC-3'; ICAM-1 (P), 5'AGTGCCGTGCCTITAGCTCCCGTG-3'; GAPDH (F), 5 '-
TGTTCTAGAGACAGCCGCATCTT-3'; GAPDH (R), 5'CACCGACCTTCACCATATTGT-3'; and GAPDH (P), 5'-TTGTGCAGTGCCAGCCTCGTCTCATA-3'.

The conditions for the PCR were as follows: $95^{\circ} \mathrm{C}$ for 10 minutes, followed by 40 cycles at $95^{\circ} \mathrm{C}$ for 15 seconds and at $60^{\circ} \mathrm{C}$ for 1 minute. Data were analyzed with a Sequence Detector $\mathrm{V} 1.6$ program (Perkin-Elmer). Relative levels of MCP-1 and ICAM-1 mRNA were expressed with normalization to GAPDH mRNA.

\section{Measurement of Myocardial Infarct Size}

The ischemic-reperfused area was measured by the triphenyl tetrazolium chloride-Evans blue method, as described previously (Gumina et al, 1996). Briefly, the coronary artery was reoccluded after 24 hours of reperfusion, and 1\% Evans blue dye in PBS was injected via a jugular vein. The left ventricle was divided into six pieces perpendicular to the apex-base axis, and the pieces were incubated with $1 \%$ triphenyltetrazolium chloride at $37 \mathrm{C}^{\circ}$ for 5 minutes. The ischemic, the infarcted, and the nonischemic areas were separated with scissors and weighed. The infarct size was expressed as a percentage of the weight of the area at risk and the whole left ventricle.

\section{Immunohistochemical Staining}

Immunohistochemical staining for activated macrophages was performed as described previously (Ono et al, 1998). The hearts of each of four rats that had received vehicle or pioglitazone ( $3 \mathrm{mg} / \mathrm{kg} /$ day) were cut into three transverse slices after 24 hours of reperfusion and embedded with OCT compound, frozen with acetone and dry ice. The embedded ventricles were cut into $4-\mu \mathrm{m}$-thick sections with cryostat, and the slides were fixed in $4 \%$ paraformaldehyde. Nonspecific background staining was limited by preincubation with $5 \%$ normal rabbit serum. The sections were incubated with the primary antibody, mouse monoclonal anti-rat macrophage (Ki-M2R, BMA) diluted to $1: 20$, at $4^{\circ} \mathrm{C}$ overnight. Biotinylated rabbit anti-mouse IgG (DAKO) diluted to 1:300 was used as a secondary antibody. Incubation with secondary antibody was performed at room temperature for 30 minutes. After incubation with avidin-biotin-horseradish peroxidase complex (Vector Laboratories) at room temperature for 30 minutes, peroxidase was visualized by 3 '-3'-diaminobenzidine. The sections were counterstained with methyl green. The primary antibody was omitted as a control for the staining of macrophages. The number of macrophages in the infarcted area was counted at a $\times 400$ magnification. The infarcted areas were measured with an image analyzer (LUSEX3; Nicon).

\section{Cell Culture and Cytokine Production by Cultured Macrophages}

We used RAW 264.7 cells, a murine macrophage-like cell line (Dainippon). RAW 264.7 cells grown in DMEM supplemented with $10 \%$ heat-inactivated FCS in a humidified atmosphere $\left(5 \% \mathrm{CO}_{2} / 95 \%\right.$ air $)$ at $37^{\circ} \mathrm{C}$, 
were seeded onto 24-well plastic plates at a density of $10^{6} \mathrm{cells} / \mathrm{ml}$. Cells were treated in the absence or presence of pioglitazone for 2 hours and stimulated by the addition of PMA (25 nM) for 24 hours. After incubation for 24 hours, the supernatants were collected. MCP-1 concentration in the supernatants was measured with an ELISA kit (Biosource International). The sensitivity of the kit was $8.0 \mathrm{pg} / \mathrm{ml}$. The results of three separate experiments were analyzed.

\section{Statistical Analysis}

Values are expressed as mean \pm SEM. The data were analyzed by one-way ANOVA, followed by Fisher's protected least significant difference. Differences were considered statistically significant at a $p$ value $<$ 0.05 .

\section{Acknowledgements}

We express our gratitude to Takeda Chemical Industries, Ltd. (Osaka, Japan) for supplying pioglitazone and to Mr. A. Yamaki for his valuable assistance in this study.

\section{References}

Ban K, Ikeda U, Takahashi M, Kanbe T, Kasahara T, and Shimada K (1994). Expression of intercellular adhesion molecule-1 on rat cardiac myocytes by monocyte chemoattractant protein-1. Cardiovasc Res 28:1258-1262.

Behr TM, Wang X, Aiyar N, Coatney RW, Li X, Koster P, Angermann CE, Ohlstein E, Feuerstein GZ, and Winaver $J$ (2000). Monocyte chemoattractant protein-1 is upregulated in rats with volume-overload congestive heart failure. Circulation 102:1315-1322.

Braunwald $E$ and Kloner RA (1985). Myocardial reperfusion: A double-edged sword? J Clin Invest 76:1713-1719.

Camp HS, Li O, Wise SC, Hong YH, Frankowski CL, Shen X, Vanbogelen R, and Leff $T$ (2000). Differential activation of peroxisome proliferator-activated receptor-gamma by troglitazone and rosiglitazone. Diabetes 49:539-547.

Chawla A, Schwarz EJ, Dimaculangan DD, and Lazar MA (1994). Peroxisome proliferator-activated receptor (PPAR) gamma: Adipose-predominant expression and induction early in adipocyte differentiation. Endocrinology 135:798800.

Desreumaux P, Dubuquoy L, Nutten S, Peuchmaur M, Englaro W, Schoonjans K, Derijard B, Desvergne B, Wahli W, Chambon P, Leibowitz MD, Colombel JF, and Auwerx J (2001). Attenuation of colon inflammation through activators of the retinoid $X$ receptor $(\mathrm{RXR}) /$ peroxisome proliferatoractivated receptor gamma (PPARgamma) heterodimer: $A$ basis for new therapeutic strategies. J Exp Med 193:827838.

Gumina RJ, el Schultz J, Yao Z, Kenny D, Warltier DC, Newman PJ, and Gross GJ (1996). Antibody to platelet/ endothelial cell adhesion molecule- 1 reduces myocardial infarct size in a rat model of ischemia-reperfusion injury. Circulation 94:3327-3333.

Hartman JC, Anderson DC, Wiltse AL, Lane CL, Rosenbloom CL, Manning AM, Humphrey WR, Wall TM, and Shebuski RJ (1995). Protection of ischemic/reperfused canine myocar- dium by CL18/6, a monoclonal antibody to adhesion molecule ICAM-1. Cardiovasc Res 30:47-54.

Haslinger B, Mandl-Weber S, Sellmayer A, Lederer SR, and Sitter T (2001). Effect of high glucose concentration on the synthesis of monocyte chemoattractant protein-1 in human peritoneal mesothelial cells: Involvement of protein kinase C. Nephron 87:346-351.

Herskowitz A, Choi S, Ansari AA, and Wesselingh S (1995). Cytokine mRNA expression in postischemic/reperfused myocardium. Am J Pathol 146:419-428.

Ikeda U, Ikeda M, Seino Y, Takahashi M, Kasahara T, Kano S, and Shimada K (1993). Expression of intercellular adhesion molecule-1 on rat vascular smooth muscle cells by proinflammatory cytokines. Atherosclerosis 104:61-68.

loculano M, Squadrito F, Altavilla D, Canale P, Squadrito G, Campo GM, Saitta A, and Caputi AP (1994). Antibodies against intercellular adhesion molecule 1 protect against myocardial ischaemia-reperfusion injury in rat. Eur J Pharmacol 264:143-149.

Jiang C, Ting AT, and Seed B (1998). PPAR-gamma agonists inhibit production of monocyte inflammatory cytokines. Nature 391:82-86.

Kakio T, Matsumori A, Ono $\mathrm{K}$, Ito $\mathrm{H}$, Matsushima $\mathrm{K}$, and Sasayama S (2000). Roles and relationship of macrophages and monocyte chemotactic and activating factor/monocyte chemoattractant protein- 1 in the ischemic and reperfused rat heart. Lab Invest 80:1127-1136.

Kakizaki Y, Waga S, Sugimoto K, Tanaka H, Nukii K, Takeya M, Yoshimura T, and Yokoyama M (1995). Production of monocyte chemoattractant protein-1 by bovine glomerular endothelial cells. Kidney Int 48:1866-1874.

Kukielka GL, Hawkins HK, Michael L, Manning AM, Youker K, Lane C, Entman ML, Smith CW, and Anderson DC (1993). Regulation of intercellular adhesion molecule-1 (ICAM-1) in ischemic and reperfused canine myocardium. J Clin Invest 92:1504-1516.

Lehmann JM, Lenhard JM, Oliver BB, Ringold GM, and Kliewer SA (1997). Peroxisome proliferator-activated receptors alpha and gamma are activated by indomethacin and other non-steroidal anti-inflammatory drugs. J Biol Chem 272:3406-3410.

Lehmann JM, Moore LB, Smith-Oliver TA, Wilkison WO, Willson TM, and Kliewer SA (1995). An antidiabetic thiazolidinedione is a high affinity ligand for peroxisome proliferator-activated receptor gamma (PPAR gamma). J Biol Chem 270:12953-12956.

Lemberger T, Desvergne B, and Wahli W (1996). Peroxisome proliferator-activated receptors: A nuclear receptor signaling pathway in lipid physiology. Annu Rev Cell Dev Biol 12:335363.

Maeshiba Y, Kiyota Y, Yamashita K, Yoshimura Y, Motohashi $M$, and Tanayama S (1997). Disposition of the new antidiabetic agent pioglitazone in rats, dogs, and monkeys. Arzneim Forsch Drug Res 47:29-35.

Matsumori A, Furukawa Y, Hashimoto T, Yoshida A, Ono K, Shioi T, Okada M, Iwasaki A, Nishio R, Matsushima K, and Sasayama S (1997). Plasma levels of the monocyte chemotactic and activating factor/monocyte chemoattractant protein-1 are elevated in patients with acute myocardial infarction. J Mol Cell Cardiol 29:419-423. 
Ono K, Matumori A, Furukawa Y, Igata H, Shioi T, Matsushima K, and Sasayama S (1999). Prevention of myocardial reperfusion injury in rats by an antibody against monocyte chemotactic and activating factor/monocyte chemoattractant protein-1. Lab Invest 79:195-203.

Ono K, Matsumori A, Shioi T, Furukawa Y, and Sasayama S (1998). Cytokine gene expression after myocardial infarction in rat hearts: Possible implication in left ventricular remodeling. Circulation 98:149-156.

Ricote M, Li AC, Willson TM, Kelly CJ, and Glass CK (1998). The peroxisome proliferator-activated receptor-gamma is a negative regulator of macrophage activation. Nature 391:7982.

Robinson EA, Yoshimura T, Leonard EJ, Tanaka S, Griffin PR, Shabanowitz J, Hunt DF, and Appella E (1989). Complete amino acid sequence of a human monocyte chemoattractant, a putative mediator of cellular immune reactions. Proc Natl Acad Sci USA 86:1850-1854.

Rollins BJ, Stier P, Ernst T, and Wong GG (1989). The human homolog of the JE gene encodes a monocyte secretory protein. Mol Cell Biol 9:4687-4695.

Sakamoto J, Kimura H, Moriyama S, Odaka H, Momose Y, Sugiyama Y, and Sawada H (2000). Activation of human peroxisome proliferator-activated receptor (PPAR) subtypes by pioglitazone. Biochem Biophys Res Commun 278:704711.

Schoonjans K and Auwerx J (2000). Thiazolidinediones: An update. Lancet 355:1008-1010.

Shioi T, Matsumori A, Kihara $\mathrm{Y}$, Inoko M, Ono K, Iwanaga $\mathrm{Y}$, Yamada T, Iwasaki A, Matsushima $K$, and Sasayama $S$ (1997). Increased expression of interleukin-1 beta and monocyte chemotactic and activating factor/monocyte chemoattractant protein-1 in the hypertrophied and failing heart with pressure overload. Circ Res 81:664-671.
Su CG, Wen X, Bailey ST, Jiang W, Rangwala SM, Keilbaugh SA, Flanigan A, Murthy S, Lazar MA, and Wu GD (1999). A novel therapy for colitis utilizing PPAR-gamma ligands to inhibit the epithelial inflammatory response. J Clin Invest 104:383-389.

Tontonoz P, Hu E, and Spiegelman BM (1994). Stimulation of adipogenesis in fibroblasts by PPAR gamma 2, a lipidactivated transcription factor. Cell 79:1147-1156.

Uchimura K, Nakamuta M, Enjoji M, Irie T, Sugimoto R, Muta $T$, Iwamoto $H$, and Nawata $H$ (2001). Activation of retinoic $X$ receptor and peroxisome proliferator-activated receptorgamma inhibits nitric oxide and tumor necrosis factor-alpha production in rat Kupffer cells. Hepatology 33:91-99.

Wayman NS, Hattori Y, McDonald MC, Mota-Filipe H, Cuzzocrea S, Pisano B, Chatterjee PK, and Thiemermann C (2002). Ligands of the peroxisome proliferator-activated receptors (PPAR-gamma and PPAR-alpha) reduce myocardial infarct size. FASEB J 16:1027-1040.

Yue TL, Chen J, Bao W, Narayanan PK, Bril A, Jiang W, Lysko PG, Gu JL, Boyce R, Zimmerman DM, Hart TK, Buckingham RE, and Ohlstein EH (2001). In vivo myocardial protection from ischemia/reperfusion injury by the peroxisome proliferator-activated receptor- $\gamma$ agonist rosiglitazone. Circulation 104:2588-2594.

Zachariae CO, Anderson AO, Thompson HL, Appella E, Mantovani A, Oppenheim JJ, and Matsushima K (1990). Properties of monocyte chemotactic and activating factor (MCAF) purified from a human fibrosarcoma cell line. J Exp Med 171:2177-2182. 